\title{
Kleine Sammlung kulturgeschichtlicher Dokumente zur ästhetischen Körperbildanthropologie
}

\author{
Modest Anthology of Cultural-Historical Documents to the Aesthetical \\ Body-Image-Anthropology
}

\section{Zusammenfassung}

Die Schönheitspflege dient seit jeher dem Mythos Alterslosigkeit. Moderne dermatokosmetische Behandlungsverfahren oder ästhetisch-chirurgische Korrekturen vermögen den bisher schicksalhaft verlaufenden Alterungsprozess aufzuhalten. Schönheit als Kompositum von Gesundheit, Jugendlichkeit und sexueller Attraktivität gewinnt in der evidenzbasierten kosmetischen Dermatologie, der auf wissenschaftlichen Erkenntnissen beruhenden Kosmetologie, zunehmend an Bedeutung. Da der Körper kosmetisch und vestimentär modifiziert als Kulturträger seiner Zeit fungiert, drückt die jeweilige Körperbildästhetik medienspezifische Fixierungen der zeitimmanenten Konventionen aus. Die kleine Auswahl kulturgeschichtlicher Aspekte bezüglich der Schönerhaltung im Wandel der Zeit möge den Hintergrund der zunehmenden Nachfrage nach dermatokosmetischen Maßnahmen gegenüber zeitgemäßer Körperbildästhetik erhellen.

\section{Abstract}

The myth of eternal no-age concerns perpetual beauty care in time. Modern dermocosmetical treatments or aesthetic-surgical revisions are able currently to delay previous fateful signs of age. Beauty, health, youth and sexual attraction reclaims increasing attention in evidencebased cosmetical dermatology, the science of beauty care. In the history of civilisation the human body serves as medium relating to beauty care and fashion which expresses contemporary history. The representative selection of changing beauty culture aspects should brighten the background of the increasing request for fashionable body aesthetic.
Die kleine Auswahl kulturgeschichtlicher Quellen bezüglich der Schönerhaltung im Wandel der Zeit möge den Hintergrund der zunehmenden Nachfrage nach dermatokosmetischen Maßnahmen gegenüber zeitgemäßer Körperbildästhetik erhellen. Schönheit als Kompositum von Gesundheit, Jugendlichkeit und sexueller Attraktivität gewinnt in der evidenzbasierten kosmetischen Dermatologie, der auf wissenschaftlichen Erkenntnissen beruhenden Kosmetologie, zunehmend an Bedeutung. Aktuelle Entwicklungen in der Dermatologie tragen dem stetig größer werdenden Bedürfnis nach präventiven Maßnahmen für ein jüngeres, gesünderes Aussehen Rechnung. Dies zeigt sich zahlenmäßig besonders eindrucksvoll an der nahezu exponentiell ansteigenden Anzahl von Publikationen zum Einsatz von Botulinumtoxin in der ästhetischen Dermatologie.

Da der Körper kosmetisch und vestimentär modifiziert als Kulturträger seiner Zeit fungiert, drückt die entsprechende Körperbildästhetik medienspezifische Fixierungen der zeitimmanenten Konventionen aus [1 -4]. Die jeweilige Weltanschauung ist maßgeblich für die Schönheitsideale einer Zeit und die daraus erwachsenden modischen Geschmacksbildungen, resultierenden Etiketten und Körperpflegetechniken, die gleichermaßen den Zi- 
vilisationsprozess dokumentieren [5,6]. Weiterhin belegen die wertvollen Toilettenutensilien und die Pretiosen der Eitelkeiten international die Bedeutung des Körperkults [7-9]. Seit Menschengedenken wird die originäre schützende Hülle des Ichs modifiziert und durch eine „zweite Haut“ sozial hervorgehoben $[10,1,12]$. Die Pflege und die ästhetische Gestaltung der Haut von Männern und Frauen lassen somit Rückschlüsse auf die spezifischen reinlichkeitskulturbezogenen, handwerklich-technischen, wirtschaftlichen, psychologischen und sozialen Bedingungen ihrer Zeit zu [13-18].

Den bereits in der Antike formulierten ganzheitlichen Ansatz greifen die moderne Psychosomatik, die anthropologische Medizin und alternative Methoden östlicher Heilkunst erneut mit evidenzbasierten Methoden unter aktuellen Fragestellungen auf. Körperpflege bedeutet neben der Verwirklichung kulturkreisabhängiger Schönheitsideale somit immer auch Seelenpflege. Nicht zuletzt sprechen aktuelle Wellness-Konzepte das uralte Bedürfnis nach körperlichem Wohlbefinden an, das eine gepflegte Haut schon immer vermittelte. Seit jeher dient die Schönheitspflege dem Mythos Alterslosigkeit. Moderne dermatokosmetische Behandlungsverfahren und/oder ästhetisch-chirurgische Korrekturen vermögen den bisher schicksalhaft verlaufenden Alterungsprozeß zu verzögern [19]. Wir stehen damit an der Schwelle zum Aufbruch in ein neues Zeitalter, weil wir uns zukünftig umfassend biotechnisch designen werden können.

In der Entwicklungsgeschichte der Kosmetik wird durch die Epochen ein strahlender Teint bevorzugt und durch pflegerische, dekorative sowie alternativ therapeutische Maßnahmen angestrebt [20]. Physikalisch reflektiert eine glatte, reine und makellose Haut als zart glänzende Oberfläche mehr Licht, die lichtmetaphorisch dem Nimbus vergleichbar eine besondere Ausstrahlung verleiht. Der Abglanz der immer jungen Göttlichkeit impliziert die Sehnsucht und die immerwährende technische Suche nach unsterblicher Vollkommenheit [21]. Kosmetisch-technische Annäherung an das göttliche Ideal wurde daher hierarchisch in Klassengesellschaften nur den gesellschaftlich herausragenden Mitgliedern zugestanden. Das perfekte, ideale Körperbild, ursprünglich den Göttern vorbehalten, wird seit der Antike bis heute angestrebt und schlägt sich in der sozialen Macht der Schönheit nieder, die schönheitschirurgisch konstruiert und inzwischen als Ware erworben werden kann.

Worin besteht die Zeit überdauernde Macht des Mysteriums der Schönheit, um die sich die Dermatokosmetik bemüht?

Schönheit lässt sich nicht festlegen. Religions-, philosophie-, literatur- und kunstgeschichtliche Annäherungen an das Unbenennbare, aber doch universell Anerkannte, dem die über den Tod hinausweisende Unsterblichkeit immanent ist, berühren klassisch daher vergleichbar die Ebene des Sakralen, des Unantastbaren, des Tabus.

Neben anderen Autoren, die sich mit ästhetischen Fragen auseinander setzten, formulierte im Jahre 1790 Immanuel Kant (1724-1804) in seinem Werk Kritik der Urtheilskraft:

„Schönheit ist das, was ohne Begriff allgemein gefällt““ [22].
Warum uns die ausgeprägte Beschäftigung mit der Schönheit des Äußeren nicht loslässt, mag mit dem Geheimnis des nicht Festzulegenden zusammenzuhängen, das wiederum eine Brücke zu Transzendentem schlägt, wonach offenbar eine latente Sehnsucht besteht.

Die nachstehende Auswahl von stellvertretenden Text- und Bildbeispielen der Kulturgeschichte soll das immerwährende Bemühen um die schöne Ausstrahlung und die gesellschaftliche Bewertung des äußeren Erscheinungsbildes interdisziplinär im Wandel der Zeit dokumentieren, ohne den Anspruch auf Vollständigkeit zu erheben.

Interessant in diesem Zusammenhang ist die Tradition der durch die Epochen bevorzugten hellen Haut verbunden mit Wohlgeruch, die sich bis auf den alles überstrahlenden Goldglanz der duftenden unsterblichen Götter zurückverfolgen lässt.

\section{Antikes Ägypten}

Eine frühe ägyptische Inschrift auf einem Wasserbehälter aus Gold aus dem Grab der Königin Hetepheres I., der Gemahlin von Senofru (um 2570-2545) und Mutter von Cheops (um 2545 - 2520), 4. Dynastie (um 2570-2450) lautet:

„Wasche Dein Gesicht in Glück und Gesundheit, indem Du Freude genießt“" [23] (Abb.1).

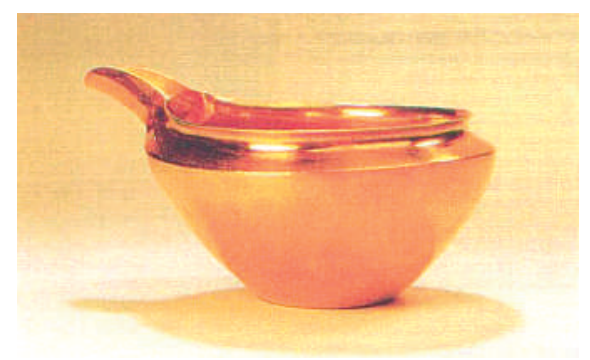

Abb. 1 Goldene Waschschüssel der Hetepheres I. aus ihrem Grab (Gise, um 2550).

Wie grundlegend wichtig das äußere Erscheinungsbild für den Menschen von damals wie auch heute ist, belegt ein Nilhymnus, der eine Notlage beschreibt:

„... es gibt keine Kleider zum Bekleiden, und nicht können die Kinder der Vornehmen geschmückt werden.

Es gibt weder Augenschminke noch Salbe, und der ohne Haare leidet Not, denn keiner kann gesalbt werden" [24].

Die Bildnisbüste der Nofretete (um 1360 v. Chr.), auch Nefertiti, Nafteta (ägyptisch, die Schöne ist gekommen) genannt, Gemahlin Amenophis IV. nachmals Echnaton (1364-1347), gilt als Inbegriff zeitloser Schönheit. Das harmonische Ebenmaß der Form, die klare Ausgewogenheit des edlen Profils, die Reinheit der Haut, die starre weit nach hinten ausladende Krone im Gegensatz zum schlanken geschwungenen Hals und die perfekte Betonung der Gesichtseinzelmerkmale durch die Schminktechnik er- 
zeugen die Spannung dieses bestechenden Ausdrucks und vermitteln damit ein zeitloses Ideal.

Die tägliche rituelle Reinigung des Echnaton findet in einem Sonnenhymnus, einem Preislied zur Verherrlichung des Sonnengottes Aton, Erwähnung:

„Du (Aton) vertreibst die Finsternis, du gibst deine Strahlen... was auf Füßen steht, erwacht: du hast sie aufgerichtet, sie reinigen ihre Körper und ziehen Leinengewänder an“ [25].

Die antiken Ägypter suchten sowohl für die Lebenden als auch für die Toten nach ewiger Schönerhaltung. Die Mumifizierungstechnik steht daher in direkter Wechselbeziehung mit der Verschönerung der Lebenden und trug zur medizinischen Kenntniserweiterung bei. Was vor Verwesung bewahrte, musste demnach auch vor Alterung schützen. Hier werden bereits die Anfänge des Mythos Alterslosigkeit gelegt, der bis heute die gesamte Kosmetikbranche sowie Dermatologen, Schönheitschirurgen und Gentechniker beschäftigt [26].

Der griechische Historiker Herodot (ca. 484-425 v. Chr.) und der griechische Geograph Strabon (ca. 63 v. Chr. - 20 n. Chr.) berichten von den Konservierungstechniken der Leichen bei den alten Ägyptern [27-30].

Bei der Mumifizierung Tutanchamuns (1347/46-1337/36 v. Chr.) wurden feinste Öle für die Illusion von Elastizität seiner Haut verwendet:

„Die Mumie wurde parfümiert und gesalbt mit der mezet-Salbe, dem Festtagsparfüm, dem safi-Öl, dem Parfüm der Begrüßung, dem chnum-Öl, dem tua-Öl, der Essenz von Zedern, der abiroSchminke, der Essenz Libyens und dem Öl baq. Man wachte darüber, dass unter dem Kinn nicht der osirische Bart fehlte“ [31].

Sprichwörtlich strahlende Schönheit wird bei den Ägyptern lichtmetaphorisch unter anderem über den Glanz des Goldes, „dem Fleisch der Götter“, dem Symbol für die Unsterblichkeit, die Ewigkeit und die lebensspendende Energie der Sonne in Götterhymnen ausgedrückt.

„Deines Gesichtes Schönheit glänzt

und leuchtet.

Du bist vollkommen,

Vor Deinem Gesicht wird man

trunken,

Gold! Hathor!“ [32].

Der Wohlgeruch als Medium der Transzendenz bildet ursprünglich eine Brücke zwischen Gott und dem Menschen. Nach ägyptischer Anschauung bewirke der wohlriechende Odem Gottes Leben, der üble Geruch dagegen zeuge vom Tod. Daher ist der Weihrauch, von dem sich der Begriff Parfum (lat. per fumum, durch Rauch) ableitet, für das Kultbildritual fester Bestandteil [33].
„Ich komme zu dir... N. N...., mit der Salbe dich zu salben, welche ausging aus dem Horusauge. Salbe dich damit; sie wird deine Gebeine verknüpfen, deine Glieder vereinen, dein Fleisch an dich binden, sie wird den widrigen Schweiß lösen, (dass er) zur Erde (fällt). Nimm ihren Duft an dich, dass dein Duft süß sei, wie (der Duft des) Ré, wenn er aufsteigt am Horizont und die Götter des Horizontes sich an ihm freuen“ [34].

Schminken verschönern und schützen den lebenden und toten Körper. Sie gehörten nicht nur als Grabbeigaben, sondern auch neben anderen Opfergaben rituell als Grundsteinbeigaben in die Gründungsgruben unter die Ecken der Außenmauern oder unter den Eingang beim Bau eines Tempels [35].

Die zerriebenen Mineralien wie zum Beispiel Malachit, der bevorzugt in den Epochen bis zum Mittleren Reich (2040-1785 v. Chr.) verwendet wurde, wurden mit Wasser, Harz oder Pflanzenölen zu einer Salbe verarbeitet. Dieser grünen Schminke wurde apotropäische Wirkung zugesprochen [36].

„Was zu diesem Gott gesagt wird im Anschluss an die beiden Lieder des täglichen Rituals:

Horus und Thot sind gekommen, um dich zu schauen im Palast.

Sie versehen dich mit dem Wasser der Urflut, mit Natronkugeln aus Elkab.

Sie geben Salbe an Deine Stirn,

Leinen an Deine Glieder,

sie bringen dir grüne und schwarze

Augenschminke dar;

Myrrhe und Weihrauch umziehen

deine Kapelle“ [37].

Ab Thutmosis III. (1490-1439/36) werden lange Röhrchen aus Schilfrohr, Holz oder Fayence als Aufbewahrungsgefäße benutzt. Es gab auch gebündelte Röhrchen. Vermutlich gab es für jede der drei Jahreszeiten eine besondere Mischung und eine vierte für den alltäglichen Gebrauch.

„Gute Augenschminke für jeden Tag - vom 1. Monat der Überschwemmung zum 4. Monat der Überschwemmubng - vom 1. Wintermonat bis zum 4. Wintermonat - vom 1. Sommermonat zum 4. Sommermonat" [38].

Im Papyros Ebers, der vollständig erhaltenen medizinischen Textsammlung der antiken Ägypter aus dem Jahr 1552 v. Chr., stehen zahlreiche medizinische und kosmetische Rezepturen für die Erhaltung, Färbung oder Entfernung der Haare, Krankenbehandlung, Körperpflege wie Haut-, Zahn- und Augenpflege, Desodorierung, Fettverminderung, gynäkologische Versorgung, Bekleidung, Parfümierung, Ungezieferbekämpfung, Raumbeduftung und Schadenszaubern gleichberechtigt nebeneinander. Eine Trennung kosmetischer von medizinisch-dermatologischen Maßnahmen gibt es nicht [39] (Abb. 2).

Die Priesterärzte waren verpflichtet vor jeder Behandlung die heilige, achtzehnzeilige Gebetsformel aus der Einleitung des Textes zu sprechen. Bei Versagen war der behandelnde Priester dadurch entlastet. Die Absicht der priesterlichen Schreiber war, die Herkunft der von ihnen aufgeführten Rezepte direkt auf die Götter 


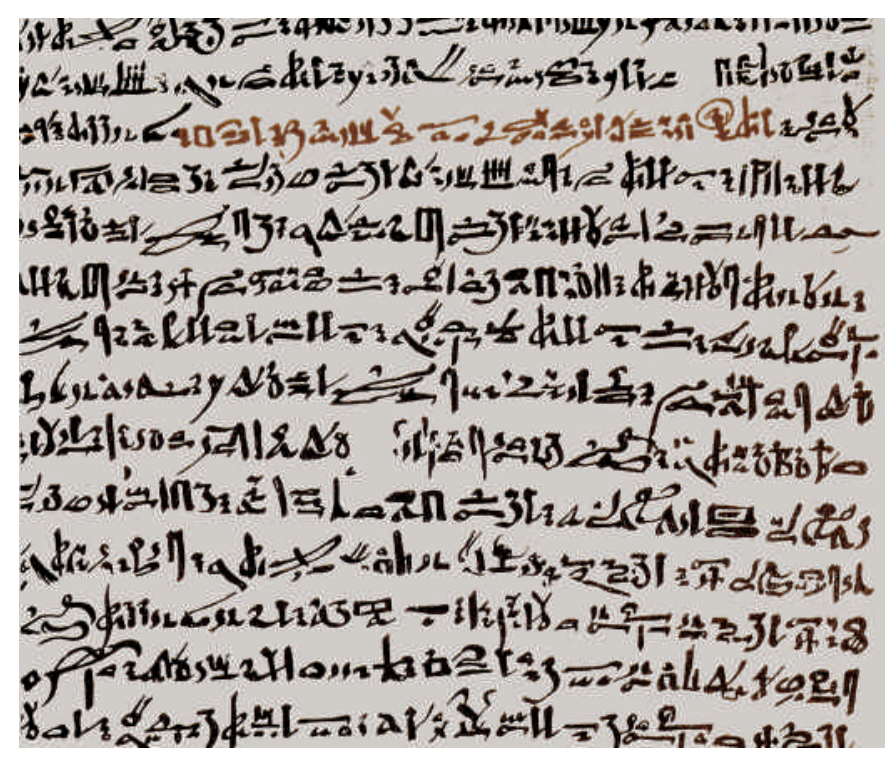

Abb. 2 Beispiel hieratischer Schrift. Detail des Papyros Ebers (1552 v. Chr.).

und Gottkönige, die selbst die höchsten Priesterärzte waren, zurückzuführen, um somit die Ausführenden zu ermächtigen.

An dieser Stelle seien ausgewählte Aspekte aus dem Inhalt des Papyros Ebers erwähnt, die die Verschönerung und Jungerhaltung durch Wiedererlangung der Gesundheit ansprechen:

„61, 6 - 8 eine andere Salbe, in den drei Jahreszeiten; 61,19-20 zur Beseitigung des eingetretenen Ergrauens und die Haare zu behandeln; 77, 14 - 15 zum Vertreiben des Fußschweisses einer Person; 86,15 - 21 Arzeneien zum Vertreiben des Ausschlages am Kopfe; 87, 1-3 Arzenei für die Reinigung des Körpers; 87, 3-4 um die Hautfarbe zu ändern; 87, 4-6 um den Leib zu verschönern; 87, 6-8 zur Vertreibung der Gesichtspickel; 87, 8-15 um dem Gesichte ein glattes Ansehen zu geben; 87, 15-17 um die Falten im Gesicht zu vertreiben; 87, 16-18 Anfang der Arzeneien zur Vertreibung der Läuse und Flöhe; 91, 2 das Riechorgan zu bezaubern; 91, 12 - 14 Kyphi, bereitet um angenehm zu machen den Geruch des Hauses oder der Kleider; 91,12 - 21 das ganze Kyphirecept.“

Rezepte aus dem Papyros Ebers:

„Ein anderes (Rezept) das Gesicht glatt zu machen:

Kuchenmehl in Quellwasser (thun); nachdem sie ihr Gesicht jeden Tag gewaschen hat, salbe sie ihr Gesicht damit.

Ein anderes:

Rindergalle, Oel, Teig, zerstoßenes Straußenei, bedet-Salz (eine besondere Natronart), hautet-Harz (?); mischen, zu einem Brei machen, in frischer Milch mischen und das Gesicht damit täglich waschen" [40].

„Kyphi, hergestellt um angenehm zu machen den Geruch des Hauses oder der Kleider. Trockene Myrrhe, Wacholderbeeren, Weihrauch, Mastix, Bockshorn und weitere zwei unbestimmte Ingredienzien, sowie Rosinen sind zu verreiben, zusammenzumengen und aufs Feuer zu stellen“ [41].

Gepflegte Ägypterinnen bedienten sich der Vorzüge der aufbereiteten Kyphi-Präparate. Zu Pastillen verarbeitet wurden diese
Kügelchen auf glühende Holzkohle zur Wohlgeruchsentwicklung gelegt. Wurde die Masse mit Honig modifiziert, konnten daraus Vaginalkugeln oder Mundpastillen gefertigt werden $[42,43]$.

\section{Antike Orientalen}

Der antike betriebene Körperkult diente der persönlichen Würde, dem Sozialstatus und dem Ansehen des zugehörigen Amtes, wobei für die Repräsentation von Männern im öffentlichen Raum auf die virile Kultiviertheit Wert gelegt wurde, die jedoch keine Maßlosigkeiten zuließ.

„Zur Zeit des medischen Königs Artaeus bat diesen einer seiner Günstlinge, ein für seinen Mut und seine Kraft berühmter Mann namens Parsondes, um Übertragung des Statthalterpostens von Babylon, nachdem er beobachtet hatte, wie verweichlicht der gegenwärtige Statthalter Nanares war, der sich rasierte und Kosmetika benutzte....Weil, antwortete Parsondes, ich mich der Ehre für mehr wert erachte, denn ich bin männlicher und dem König nützlicher als du, der du rasiert bist, deine Augen mit Stibium untermalst und dein Gesicht mit weißem Blei schminkst“ [44].

Heller Teint wurde im Mittelmeerraum als statuserhebend empfunden und mit Hilfe von Schminken erzeugt. Ein orientalisches Bleichmittel für die Haut:

„Ein Batikha genannter Puder für den Teint, den man in allen Harems zum Bleichen der Haut benutzt, wird folgendermaßen bereitet: Man zerstößt in einem Mörser die Schalen einiger Kaurimuscheln, Borax, Reis, weißen Marmor, Kristall, Tomate, Eier und Helbas (ein in Ägypten gesammelter bitterer Same), vermischt dies mit dem Mehl von Bohnen, Kichererbsen und Linsen und füllt das Ganze in eine Melone, indem man es mit Fruchtfleisch vermengt. Die Melone wird dann bis zum völligen Ausdörren der Sonne ausgesetzt und zu einem feinen Pulver zermahlen“ [45].

\section{Antike Griechen}

Zum Aphroditemythos der „Schaumgeborenen“ aus der Theogonie des griechischen Dichters Hesiod (um 700 v. Chr.), der in der Kunst der Renaissance ein beliebtes Sujet wurde, weil er ewige Jugend, Schönheit und Attraktivität spiegelte:

„Die Schamteile aber, nachdem er sie abgeschnitten hatte mit dem Stahle und hintergeworfen hatte vom Festland ins brandungsreiche Meer, da trieben sie lange Zeit nur so über die Fläche hin. (Im Machtkampf kastrierte Kronos seinen

Vater Uranus.)

Rundherum aber trat dann weißer Schaum von dem unsterblichen Körperteil her zutage, und da drinnen wurde ein Mädchen genährt. Zuerst kam sie an (die Insel) Kythera, die hochheilige, heran; von da aus gelangte sie dann zur ringsumflossenen (Insel) Kypros. Heraus stieg da die achtungsgebietende schöne Göttin, und ringsum sproßte da Gras unter den flinken Füßen. Die heißt Aphrodite bei den Göttern und Menschen, weil sie im aphros ( = Schaum) aufwuchs, und heißt Kythereia, weil sie in 
Kythera antrieb; Kypros-geborene (heißt sie) aber, weil sie auf der ringsumtosten (Insel) Kypros entstanden ist, und schamgliederliebend (heißt sie), weil sie aus den Schamgliedern ans Licht trat" [46].

In der Hymne auf die mystische Ausstrahlung der Aphrodite des griechischen Dichters Homer (8. Jh. v. Chr.) wird die Schönheit des Zusammenspiels von Bekleidung, Schmuck, heller Haut und göttlicher Aura offenbar:

„... und thaten ihr göttliche Kleider

An und setzten ihr ferner den schön aus Golde gemachten

Kranz aufs heilige Haupt und hängten ihr dann an

Die Ohren

Blumengeschmeid aus Erz und gepriesenem Golde

Verfertigt.

Aber den zierlichen Hals und den schneeweißstrahlenden

Busen

Schmückten mit goldener Ketten Geschmeide sie,

welche die Horen

Selber geschmückt, die mit Gold umkränzeten,

wann zu der Götter

Anmuthseligem Reih'n und dem Vaterpalaste sie gingen“ [47].

Der griechische Philosoph Platon (427-347 v. Chr.) entwirft in seinem Werk Die Rede des Timaios über das Entstehen der Welt den Schöpfungsmythos der Haut, Haare und Nägel:

„Ferner war es nicht, wegen der nach beiden Seiten hin das Maß überschreitenden Verschiedenheit der Jahreszeiten, tunlich entweder zu gestatten, dass der Kopf allein mit einer nackten Knochenhülle versehen sei, oder dagegen es geschehen zu lassen, dass er von des Fleisches Überfülle umgeben, stumpf und der Sinneswahrnehmung unzugänglich werde; sondern es wurde von dem fleischigen, nicht ganz dabei vertrocknenden Wesen ein größerer, davon zurückbleibender Überzug ausgeschieden, den man jetzt die Haut nennt; ... Aber die Finger und Zehen umgebende, aus drei Bestandteilen, Sehnen, Haut und Knochen, zusammengesetzte Verflechtung wurde, ausgetrocknet, zu einer harten, aus der gemeinsamen Vereinigung dieser drei Stoffe gebildeten Haut, welche aus diesen Mitursachen gewirkt, von dem eigentlich verursachenden Verstand zum Wohle späterer Geschlechter gebildet. Denn diejenigen, welche uns zusammenfügten, wussten, aus den Männern würden die Frauen sowie die übrigen Tiere hervorgehen, und sahen voraus, gar manches Vieh werde zu manchem Behuf der Nägel bedürfen; daher ließen sie sogleich beim Entstehen der Menschen die Anlage der Nägel sich gestalten. Das erwogen sie, und aus solchen Gründen erzeugten sie auf der Oberfläche der Glieder Haut, Haare und Nägel“ [48].

Bei dem griechischen Dichter Antiphanes (1. Hälfte und Mitte des 4. Jhs. v. Chr.) erfährt man von einem vornehmen Griechen, der exklusiven Körperkult betreibt:

„Er badet tatsächlich

In einer großen vergoldeten Wanne und taucht sein Füße Und Beine in schwere ägyptische Salben;

Kiefer und Brust reibt er mit zähflüssigem Palmöl ein, Und beide Arme mit einem nach Minze duftendem Auszug; Augenbrauen und Haar mit Majoran,
Knie und Nacken mit einer Essenz aus zerstoßenem

Thymian“ [49].

\section{Antike Römer}

Der römische Dichter Ovid ( Publius Ovidius Naso, 43. v. Chr. bis etwa $17 \mathrm{n}$. Chr.) beschreibt in einem erhaltenen Fragment über Kosmetik Medicamina faciei femineae eine Gesichtsmaske für die Schönheit:

„Lernt jetzt, wie das Gesicht, wenn der Schlaf euch befreit die zarten Glieder, sich glänzend schmücke mit strahlendem Weiß. Gerste zu Schiffe gesandt, von der Tenne des libyschen Landmanns werde zuerst aus der Spreu und aus den Hülsen gelöst. Nimm zehn Eier alsdann; durchfeuchte dasselbe Quantum Erbsen; doch muss zwei Pfund wiegen Gerste für sich, hast du die Masse dann gut an der Luft im Winde getrocknet, mahle die Eselin sie langsam mit schartigem Stein! Auch das Geweih, das zuerst langlebigen Hirschen entfallen, reihe dazu. Vier Lot nimm von dem richtigen Pfund. Wenn du gehörig es dann mit dem stäubenden Mehle vermischt hast, musst du das alles mit Fleiß beuteln im bauchigen Sieb. Reibe mit kräftiger Hand von zwölf Narzissen die Zwiebeln (ohne die Haut), doch nimm reinliches Marmorgeschirr: Thu zwei Unzen dazu von Tustischen Körnern und Gummi, und neunmal so viel Honig noch gieße darein. Wenn du dir dann das Gesicht einreibst mit der obigen Mischung, wird es glänzend, dass selbst heller dein Spiegel nicht strahlt" [50].

\section{Mittelalter}

Im scholastischen Weltbild wurde die Schönerhaltung des Körpers unter dem Vanitasaspekt in die Erhöhung der schönen Seele transzendiert. Das Geistige überdeckte das Weltliche und somit erfuhr der Begriff des „Fleisches“ durch das Christentum eine Abwertung, weil er mit niedriger, sündiger Triebhaftigkeit besetzt wurde. Dies blieb nicht ohne Folgen für die Körperpflege.

„Häßlich ist das Verfehlen des Ideals und damit auch zugleich bestimmt als das ontologisch Schlechte. Thomas von Aquin versteht Häßlichkeit als ,privatio ordinis‘ bzw. ,privatio pulchritudinis‘. Der ,privatio'-Charakter macht das Häßliche zu einem Analogon von ,malum', das ja als ,privatio boni` definiert wird. Das Häßliche ist die ästhetische Unidee, und bleibt dennoch ein integrierendes Moment der Ästhetik. ... Zahlreiche Beispiele aus der afz. Literatur sowie eine Reihe von afz. Sprichwörtern belegen, dass die von Theologie und Philosophie verfochtenen Lehren der, pulchritudo‘ und ,turpitudo،, aufs Einfachste reduziert, in den volkstümlichen physiognomischen Anschauungen wiederzufinden sind. Wer häßlich ist, ist böse; häßlich ist er, weil er böse ist, seine äußere Gestalt ist eine Strafe für seine Sünden und ein Zeichen dafür, dass er nicht unter der Gnade Gottes steht“" [51].

Auch der Kirchenlehrer und Zisterzienser Bernhard von Clairvaux (um 1090 - 1153) misstraut der äußeren irdischen Schönheit, verweist jedoch auf die Mystik der inneren himmlischen. Die heidnische, der eitlen Schönheit dienende Lichtmetaphorik wird auf die christliche transzendente übertragen. 
„O vere pulcherrima anima quam, etsi infirmum inhabitantem corpusculum, pulchritudo caelestis admittere non despexit, angelica sublimitas non reicit, claritas divina non repulit!“

(O Seele, die du wahrhaft die schönste bist, auch wenn du einen schwachen, erbärmlichen Leib bewohnst; die himmlische Schönheit fand dich würdig, dich bei sich aufzunehmen; die engelgleiche Erhabenheit hat dich nicht zurückgewiesen, das göttliche Licht dich nicht verworfen!) [52]

Der kulturelle Austausch mit dem Orient durch die Kreuzzüge vom Ende des 11. bis zum Ende des 13. Jahrhunderts hat zu mehr sinnenfreudiger Diesseitigkeit beigetragen. Die Kreuzzüge kultivierten die europäische Ritterschaft, verfeinerten die Sitten und die Körperpflegekultur. Höfische Sängerwettstreite, Minnekult und Miniaturmalereien kennzeichnen die höfische Kultur. Bemerkenswert ist in diesem Zusammenhang die Manessische Liederhandschrift, die auf 137 Abbildungen über die Zeit informiert (Abb. 3).

Die helle Haut wird als Schönheitsideal in der höfischen Lyrik des mittelhochdeutschen Dichters von Heinrich von Morungen (gest. 1222) beschrieben:

„Weh mir, soll fürder leuchten nicht

mir durch die dunkle Nacht

Ihr Leib, wie Schnee so weiß und licht,

in voller Schönheit Pracht?

Es täuschen mich die Augen mein;

Ich dacht, es möchte sein

Des lichten Mondes Schein -

Da tagte es! ...“ [53].

Der französische Hofchirurg Henri de Mondeville (1260-1320) gilt als einer der ersten Ärzte, der zwischen Medizin und kosmetischen Maßnahmen zur Verbesserung des Äußeren unterscheidet. Von da an werden kosmetische und dermatologische Behandlungen weitgehend getrennt [54].

\section{Renaissance}

Die auf antiken Schönheitsidealen basierende Körperbildästhetik des Humanismus fördert die Neubewertung subjektiver Körperpflegemaßnahmen des Individuums. Körpergefühle, Sauberkeitsbedürfnisse und Schönheitsempfinden gehören zum Bereich individuellen Erlebens und repräsentieren den jeweiligen gesellschaftlichen Code. Der Körper fungiert nun als Ort subjektiver ästhetischer Erfahrung [55 - 57].

Der Schriftsteller und Diplomat Baldassare Castiglione (1478 - 1529) entwickelt das tugendbesetzte Leitbild männlicher Lebensart, den uomo universale, dem die gentildonna, die edle Dame, ebenbürtig ist, in seinem Werk Il Cortegiano (1528), das die humanistische Frage nach der Differenzierung zwischen Geburts- und Tugendadel aufwirft.

„Nach meiner Ansicht ist es aber von großer Wichtigkeit, dass unser Hofmann zierlich und geschmackvoll gekleidet sei und eine gewisse Gleichmäßigkeit in bescheidenem Putz zeige, je-

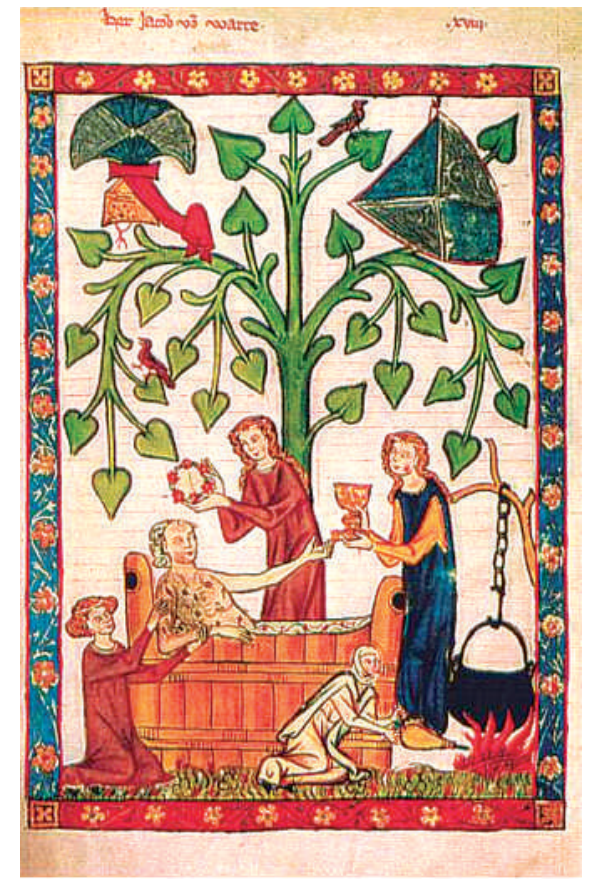

Abb. 3 Der Minnesänger Jakob von der Warte im Badezuber von Rosenblüten bedeckt im Garten, Miniatur (Cod. Pal. Germ. 848 [Große Heidelberger Liederhandschrift "Codex Manesse"], fol. 46 verso, Universitätsbibl. Heidelberg).

doch nie weibische oder eitle Art, auch nicht in einem Ding mehr als in einem andern. So sehen wir viele, die viel Mühe auf die Pflege ihres Haars aufwenden, alles andere aber vernachlässigen; ein anderer achtet nur auf die Schönheit seiner Zähne, ein dritter auf die des Barts, ein vierter auf die der Stiefel, ein fünfter und sechster auf die des Baretts und der Mütze. Davon kommt es, dass an solchen Leuten das Schöne wie etwas Geborgtes auffällt, während das Garstige für ihnen eigen gehalten wird. Solchen übeln Brauchs wird sich unser Hofmann, wenn er meinem Rat folgt, enthalten und sich nach reiflicher Überlegung entschließen, als wer er genommen werden will, und danach seine Kleidung einrichten, so dass sie ihn in seiner Absicht unterstützt, damit er auch von solchen, die ihn weder haben reden hören, noch handeln sehen, auf eine ihm angenehme Weise beurteilt werde“ [58].

An anderer Stelle aus Il Cortegiano (1528):

„... überall verzehren sich die Damen in der Sehnsucht, schön zu sein, oder, wenn das unmöglich ist, wenigstens für schön zu gelten; versagt daher die Natur irgendwie, so sind sie gezwungen, zur Kunst Zuflucht zu nehmen. Dann verwenden sie viele Sorgfalt und Mühe darauf, ihr Gesicht herzurichten, raufen sich die Haare aus den Augenbrauen und von der Stirn und wenden eine Menge lästiger Mittel an, wovon Ihr Damen glaubt, sie blieben den Männern geheim, obwohl sie jedermann bekannt sind“ [59].

Dem Ideal der standesabgrenzenden schneeweißen Haut wurde in der Renaissance weiterhin reichlich mit Bleiweiß nachgeholfen

Barock

Das kulturell wegweisende Frankreich der ersten Hälfte des 17. Jahrhunderts prägt den Begriff Mode. Der Stil des absolutistischen Zeitalters vereint alle künstlerischen, geistesgeschichtli- 
chen und gesellschaftlichen Bedürfnisse zu einem Gesamtprogramm. „Barock“ ist ein Lebensgefühl und durchdringt die Plastik, die Malerei, die Architektur, die Gartengestaltung, die Musik, die Religiosität, die Literatur, das Mobiliar, das Kostüm, die Haartracht, die Gebärdensprache und die Sprechweise. Körpermodifikation bedeutet Überhöhung des Naturzustandes durch künstlerische Umgestaltung und bewirkt damit die standesabgrenzende Distinktion.

„Wie der Raum beherrscht, so sollte die Zeit stillgelegt werden. Ziel war es, den Augenblick der vollkommenen Grandeur und der höchsten Lust in Ewigkeit zu verlängern. Man erfand Puder und Schminke, um dem Altern den Kampf anzusagen, man kleidete die Kinder wie Erwachsene und die Greise wie Jugendliche, verwandelte durch Feuerwerke die Nächte in Tage, schuf mit Gewächshäusern den ewigen Frühling“ [60].

Wasser wurde nur sparsam zugunsten der reinigenden Wirkung der Leibwäsche gebraucht. Dies war in einer Zeit der Fäkalgruben vor der Schwemmkanalisation eine sinnvolle Vorsichtsmaßnahme $[61,62]$.

„Morgens soll von frischem Wasser deine Hand gewaschen sein, und deine eben erwachten Augen sollen von diesem feucht sein“ [63].

Der italienische Baumeister, Bildhauer und Maler Gian Lorenzo Bernini (1598 - 1680) bemerkt in seinem Reisetagebuch zur Kritik an seinen Verbesserungsentwürfen für den Louvre als Architekt:

„Dauernd dieses Geschwätz von Aborten und Abwasserleitungen“" [64].

Der Le Mercure galant von 1677 berichtet:

„Da die Sauberkeit ein gewisser Anstand der Kleidung einer Person ist, ebenso wie die feine Gesittung Anstand in den Handlungen gegenüber anderen bedeutet, ist es, wenn wir sauber sein wollen, notwendig, unsere Kleidung unserer Körpergröße, unserem Stand anzupassen.... Das unerläßliche Gesetz, das man bei der Sauberkeit zu beachten hat, ist die Mode, ihrer absoluten Herrschaft muss sich der Verstand beugen“ [65].

Zu den Aufgaben der Wäscheaufseherin bei den Ursulinerinnen aus den Réglements des réligieuses ursulines von 1705 gehörte die fürsorgliche Kontrolle der Reinlichkeit:

„Sie soll den Schlüssel zu den Truhen derjenigen haben, die nicht fähig sind, sich selber um ihre Wäsche zu kümmern: Sie soll ihnen zweimal in der Woche weiße Wäsche geben oder öfter, wenn die Oberin es für notwendig erachtet, und sie soll sie mittwochs und samstags auf ihre Betten legen“ [66].

Aus einem zeitgenössischen Bericht aus Anlass der Vermählung Leopolds I. in Wien aus dem Jahr 1667 geht die gesellschaftliche Wahrnehmung ranghoher Damen hervor:

„Die Fenster an den beiden Burgen waren alle von den anwesenden Damen und hohem Frauenzimmer besetzet, welche mit ihrer trefflichen Schönheit unter dem schimmernden und spielen- den Glanze ihres überaus kostbaren Kleiderschmucks gleich wie Sterne am Himmel funkelten“ [67].

Die Sozialgeschichte der Gerüche im Barock zeugte nicht nur von dem Vergnügen und der Lebensart, sondern wies auch auf Missstände hin:

„Der aromatisierte Mensch verbessert seine Atmosphäre durch starke Gerüche, gegebenenfalls sogar durch die schweren Ausdünstungen von Moschus, Ambra oder Zibet. Wer sich über die Maßen parfümiert, schützt nicht nur sich selbst, er reinigt auch die ihn umgebende Luft. Nimmt es da noch Wunder, dass die Mode tierischer Riechstoffe mit deutlichem Fäkalgeruch sich lange Zeit durchsetzen konnte, ja dass offenbar allein die Autorität Ludwigs XIV. in der Lage war, sie zumindest in Versailles vorübergehend einzudämmen?“ [68].

\section{Rolkoko}

Mediziner warnen vor den Gefahren des Schminkens. Die höfisch geforderte Künstlichkeit, Geziertheit und Selbstbeherrschung, die die natürliche Sentimentalität zu unterdrücken gedachte und der Dekadenz Nährboden verlieh, wird im aufkommenden Zeitalter der Empfindsamkeit zunehmend kritisiert .

Man verwendete unter anderem Benzoe-Schminkwasser, Jungfer $=$ Milch, Englische Jungfer $=$ Milch, Holländisches Schminkwasser, Nürnberger Schminke, Schminkwasser der Großherzogin von Florenz, Venetianisches Wasser. Man benutzte giftige Bleiweißschminke und giftigen Spanischen Menniganstrich, Schminkläppchen, auch Bezette rubra oder Torna solis oder spanische Schminkläppchen genannt, Rosentücher, Leinwand- oder Creponflecke, die mit Cochenille gefärbt wurden, Lackküglein zur Wangenfärbung, lackhaltigen Rothen = Mund = Balsam, daneben Pomaden für Gesicht und Lippen, falsche Zähne, Masken aus weißem Wachs, Froschleich = Wasser, Wallrath und Campffer, Mouchen oder Schminkpflästerchen und parfümierte Puder $[69,70]$.

Kritik am Schminken der Damen des Predigers und Volksschriftstellers Abraham a. S. Clara, eigentlich Johann Ulrich Megerle (1644-1709):

„1) Abrahamisches Gehab dich wohl: ihre Falten überschmiert sie mit Curnisoll, Bleyweiß und anderer Schminke, hat beynebens etliche helffenbeinerne Zähn im Maul, welche ihr der Artzt eingesetzet.

2) Jungfern-Anatomie: wenn ich erzehlen solt, die Schminken alle sagen, müßt ich vier Wochen erst die Apotheker fragen, wodurch die Stirne gläntzt, wodurch die Backen roth, das ist dem Jungfernvolck ihr täglich liebes Brodt. Das müssen sein Zibeth, der Bisam, Balsam = Buder, es muss bestrichen seyn das gantze Leib = Gepluder mit Salben bester Art. Es wäscht, es badet sich das stoltze Jungfer-Thier sehr wunder-wunderlich... sie pflegen sonsten auch die Backen scharff zu reiben, ja jene Jungfer aß nicht mehr als Sauerkraut: vermeinte dadurch auch zu kriegen schöne Haut“" [71]. 
Im 18. Jahrhundert wurde eigens ein Möbel für den Schminkkult entwickelt:

„Dies ist das Triumphmöbel im Appartement der Frau, dieser Tisch, der von einem Spiegel überhöht wird, der gleich einem Altar mit Spitzen verziert und gleich einer Wiege mit Musselin umhüllt ist, der mit Zaubertränken und Zierraten, mit Schminken, Pasten, Schönheitspflästerchen, mit Parfüms, Zinnober, mineralischem Rot, vegetabilischem, chemischen Weiß, Adernblau, Mailleessig gegen die Runzeln bedeckt ist, dazu kommen die Bänder, die Tressen und Aigretten, die bezaubernde Kleinwelt der Koketterien des Jahrhunderts, dem in einer Puderwolke Ambraduft entströmt!“ [72] (Abb. 4).

\section{Aufklärung}

Zunehmend geriet die Gefährlichkeit der Schminken der Aristokratie in die Kritik. Ratgeber der Zeit empfehlen die natürliche Schönheit zu unterstützen und stärken damit bürgerliche Wertvorstellungen.

Aus Anmuth und Schönheit aus den Misterien der Natur und Kunst für ledige und verheirathete Frauenzimmer mit Kupfern, Berlin 1797:

„Betrachten wir die Schönheit von ihrer medicinischen Seite, so ergiebt sich, dass drei Hauptbedingungen zu einem schönen Gesicht erfordert werden:

- Der lebendige Reiz der weiblichen Gesichtsbildung hängt unstreitig von der größern Beweglichkeit der Gesichtsmuskeln, von der leichtern Ausdehnbarkeit der Blut = und Wassergefäße ab; hierzu tragen vorzüglich die kleinen Fettkügelchen bei, die unter der Haut, besonders in der Gegend der Wangen und des Mundes zerstreut liegen, jeden Muskel umgeben, denselben beweglicher machen, die Haut auflockern und zugleich die Weichheit und Geschmeidigkeit derselben erhalten. Die kleinen Härchen, womit die Oberfläche der Haut, wie mit dem zartesten Pflaumen bedeckt ist, verstärken die Wirkung jener Lebendigkeit. Wird dieses zarte Fett ausgetrocknet oder verzehrt, so ist jedes Schönheitsmittel unnütz.

- Ein zweites Erforderniß ist der gute Zustand der Schweißlöcher des Gesichtes; sind diese gehörig offen, und an ihren in die Haut gehenden Spitzen etwas erhaben und locker, so hat das Gesicht jenes reizende jugendliche Ansehen, was es aber durch öfteres Waschen und vorzüglich durch zusammenziehende und verstopfende Mittel verliert.

- Die dritte Bedingung, worauf die Schönheit beruht, ist ein gutes, gesundes und nicht stockendes Blut....

Schädliche Schönheitsmittel:

Es gibt bekanntlich rothe und weiße Schminke. Die gewöhnlichsten weißfärbenden Mittel sind: Der Sublimat, weißer Vitriol, Perlen, Benzoe, Wismuth, Bleiweiß, und hiervon vorzüglich das Kremserweis, Koboldpräcipitat, Alabaster und weißer Puder. Roth färbt Karmin, Zinnober, Kugellack, die mit Zinnober gemachte Seife, Talch (ein venetianischer kalkartiger Stein) mit Saflor gefärbt, und die Blume der Amaranthe. Brandwein macht auch auf eine kurze Zeit die Haut roth, wegen seiner erwärmenden und zusammenziehenden Kräfte. Die Haare, Augenbrauen

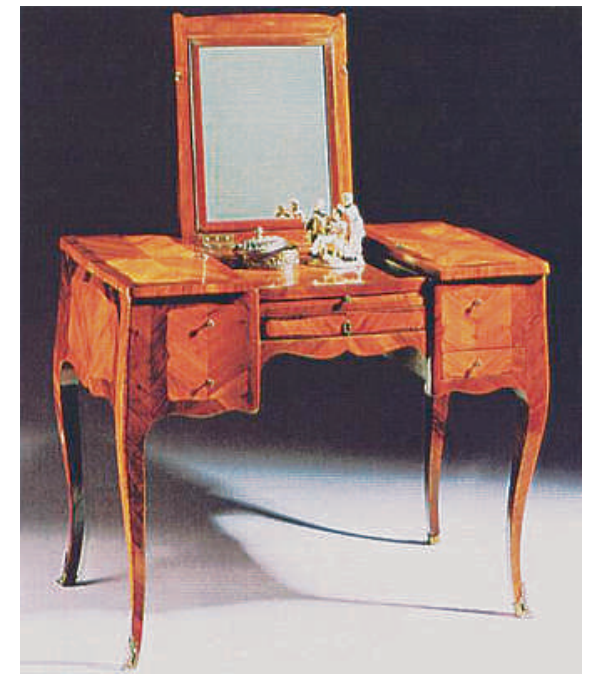

Abb. 4 Poudreuse. Rosenholz, Palisander, Messing, Frankreich, um 1750.

und Augenwimpern werden mit kalciniertem Kupfer schwarz gefärbt. Die Namen, welche die Parfumeurs ihrer Komposition geben, als Rouge à la Reine, oder Rouge vegetal, aus Talch und Saflor, Rouge de Portugal, aus Karmin und Talch, Blanc de perles, u. s. w. sind bekannt.

- Wenn die Wirkung dieser Mittel auf den menschlichen Körper beurtheilt, so wird sich leicht ergeben, dass einige davon die Haut reizen und angreifen, andere hingegen dieselbe zusammenziehen. Das erstere thun die Mittel von Quecksilber, Kobold, Kupfer; das letztere Vitriol, Blei, Brandwein, einige nur in einem größeren Grade als die andern. Besonders saugen die kalkartigen Schminken das feine Oehl in sich, welches die unzähligen unter der Haut liegenden Talgdrüsen absondern, wovon eigentlich der schöne Teint entsteht....

- Eine andere schädliche Wirkung der Schminke ist, dass sie, naß oder trocken aufgerieben, die feinen Poren der Haut verstopfen, und also die unmerkliche Ausdünstung verhindern.... Die Haut muss wegen dies ihr entzogenen feinen Oels alle Geschmeidigkeit verlieren, rauh werden, in mehlige Schüppchen zerspringen, abwelken, und in unförmliche Ringeln zusammenschrumpfen, die in dem menschlichen Gesicht ein widriges Ansehen machen, wenn hingegen jene Falten, die das Alter auf dem Gesichte gezogen hat, demselben eine gewisse Würde geben“ [73].

- „Die Schminke ist die gefährlichste Feindinn für weibliche Schönheit; sie ätzt nicht nur die feinen Gesichtszüge aus, sondern sie verdrängt, wenn ihre Anstrich auch der feinste von der Welt ist, das sprechende Leben in der Physiognomie“ [74].

- „Wenn man diese Vorschriften genau beobachtet hat, so kann man allmählich anfangen, die Haut durch folgendes Wasser gelinde zusammen zu ziehen. Man nehme:

- Aus nur wenig hart gesottenem

- Eyweis gepreßtes Wasser 2 Eßlöffel voll.

- Zitronensaft. . ${ }^{1 / 2}$

- Fein gestoßenen Alaun 3 Gran.

- Wegbreitwasser. ${ }^{1} / 2$ Quart.

- Dies alles vermische man zusammen, und wasche oder benetze nur das Gesicht des Tages einigemal damit.

- Eine Haut, die bei scharfer Luft in der Kälte leicht aufspringt, wird ohne Schaden dadurch verbessert, wenn unter das Waschwasser die Hälfte weißer Wein oder ein Dritheil Eau 
d'Arquebusade oder ein Sechstheil Franzbrandwein gegossen wird. Eine sehr zarte und feine Haut des Gesichts kann z. B. auf Reisen der Sonnenhitze nicht ohne Nachtheil ausgesetzt werden; man schützt dieselbe sehr leicht dadurch, dass man das Gesicht mit Eyweiß in Rosenwasser zerschlagen, am frühen Morgen vermittelst eines weichen Schwämmchens benetzt, und erst am Abend wieder abwäscht“ [75].

\section{Klassizismus}

Im Zeitgeist der Aufklärung kritisiert der deutsche Philosoph Christian Garve (1742 - 1798) mit seiner philosophischen Untersuchung Über die Moden (1792) von den mit dem Luxus der Moden verbundenen Aufwand:

„Eine allgemeine Bemerkung in Absicht dieses ganzen zweiten Hauptzweiges des Modischen oder der Gewohnheiten ist diese. Je zahlreicher und zusammengedrängter, und je verfeinerter zugleich dadurch die Gesellschaft wird; je mehr der Luxus und der Hang zu Vergnügungen zugleich mit dem Geschmacke und der Wissenschaft in denselben steigt: desto mannigfaltiger werden die Anordnungen und Konventionen, nach welchen Zeit, Form und Methode der gesellschaftlichen Verrichtungen und Zeitvertreibe bestimmt werden; - desto einfacher hingegen, freier und geringer an der Zahl werden die Formen der Höflichkeit“ [76].

\section{Jahrhundert}

Bürgerlichkeit, Sauberkeit und Anstand begründen das neue Hygieneverständnis im Biedermeier, das didaktisch zur Bürgerpflicht erhoben wird und auf die Moral im Kampf um soziale Ungerechtigkeiten übertragen wird [77].

Bei dem deutschen Philosophen Arthur Schopenhauer (1788-1860) sind das Ich und der Leib ein und dasselbe sowie der Körperausdruck die Spiegelung der Objektivität des Willens. Aus seinem Werk Parerga und Paralipomena II (1851):

„Denn das Gesicht eines Menschen sagt gerade aus, WAS ER IST; und täuscht es uns, so ist dies nicht seine, sondern unsere Schuld. Die Worte eines Menschen hingegen sagen bloß, was er denkt, öfter nur, was er gelernt hat, oder gar, was er zu denken bloß vorgiebt“" [78].

Das gehobene Bürgertum informiert sich über zeitgemäße medizinisch empfohlene Methoden einer moralisch vertretbaren Reinlichkeitskultur, die vordergründig der Gesunderhaltung des Körpers und erst zweitrangig dessen ästhetischer Verbesserung dient.

Rezepte aus dem Toilette-Lexikon für die elegante Welt. Kosmetisches Nachschlagebuch für Damen und Herren zur Erhaltung und Erhöhung ihrer Schönheit, Anmuth und Gesundheit von Dr. Wilhelm Gollmann, Verlag von Franz Wagner, Leipzig 1860:

„Erhitzte Gesichtsfarbe zu mäßigen. Waschmittel: Man nimmt 4 Loth mageres Kalbfleisch, kocht es mit einem Seitel Wasser bis auf die Hälfte ein, seiht die Flüssigkeit nach dem Erkalten durch und wäscht sich damit an heißen Sommerabenden“ [79].

„Gesichtshaut rein zu erhalten. Ein gutes Waschwasser zu diesem Zwecke verfertigt man also: Man nimmt eine Hand voll Hamburger Hafergrütze und kocht sie in einem Topf mit 1 Seitel Wasser. Wenn es kalt ist, gießt man es durch ein Tuch in einen porzellanenen Topf, thut 24 recht klein gestoßene bittere Mandeln, $1 / 2$ Seitel ungesalzenes Rosenwasser und 12 Tropfen Benzoetinktur dazu, rührt alles gut durcheinander, ringt es durch ein Leinentuch und füllt es in eine Flasche“ [80].

Auf dem Boden bürgerlich-anständiger Sauberkeit gediehen kontrastreiche Parallelwelten sinnlich betonter Körperästhetik. Im folgenden Gedicht Der Duft aus Les Fleurs du Mal von 1861 beschreibt der französische Schriftsteller Charles Baudelaire (1821 -1867) eine schwüle olfaktorisch-synästhetische Vision:

„Leser, hast du bisweilen schon verspürt, Rauschhaft und dem Genusse hingegeben, Die Weihrauchdüfte, die in Kirchen schweben, den Moschus, der in Beutel eingeschnürt? Tief zauberhafter Reiz, darin verzückt Vergangenes, das sich gegenwärtig zeigt! So wie der Liebende zum teuren Leib geneigt Erlesene Blüten der Erinnerung pflückt. Ihr so geschmeidiges und schweres Haar, Das wie ein Duftgefäß den Raum belebte, Ein wilder, raubtierhafter Hauch umschwebte; Der Musselin und Samt der Kleider war So von dem Duft der reinen Jugend voll, Dass ein Geruch von Pelzwerk ihm entquoll“ [81].

Die Firmengründungen der siebziger Jahre, der Gründerjahre, begünstigen das zunehmende Repräsentationsbedürfnis und das damit verbundene Modekonsumverhalten sowie das dekadente Salonleben der „Neureichen“, die um 1871 in Deutschland nur etwa zehn Prozent der Gesamtbevölkerung ausmachen [82].

Der französische Schriftsteller Joris-Karl Huysmans (1848-1907) beschreibt in seinem Werk A rebours (Gegen den Strich) von 1884, das zum Kultbuch avancierte, die Schminkutensilien eines Dandys:

„Er verkorkte sorgfältig die Phiolen und nützte die Gelegenheit, um der Unordnung seiner Schminkutensilien abzuhelfen. Seit seinem Einzug in Fontenay hatte er sie nicht mehr angerührt, und er war jetzt fast erstaunt, diese einst von so vielen Frauen besichtigte Sammlung wieder vor sich zu sehen. Flacons und Töpfchen stapelten sich. Hier enthielt ein Porzellandöschen aus der grünen Familie den Chnuda, diese herrliche, weiße Creme, die, aufgetragen auf die Wangen, unter der Lufteinwirkung in ein zartrosa und dann in ein solch echtes Hochrosenrot umschlägt, dass sie die vollkommene Illusion einer gut durchbluteten Haut schafft; dort bargen mit Perlmuttschnecken ausgelegte Lackkästchen japanisches Gold und das an die Flügelfarbe der spanischen Fliege erinnernde Athener Grün; Gold- und Grüntöne, die sich sofort in Purpur verwandeln, wenn man sie befeuchtet; neben den Töpfchen mit Haselnußpaste, Haremsserkis, 
Kaschmirlilienmilch, Erdbeer- und Holunderlotionen für den Teint, neben den mit Tuschelösungen und Rosenwasser für die Augen gefüllten Fläschchen lagen zwischen Luzernebürsten für das Zahnfleisch kunterbunt durcheinander: kleine Gerätschaften aus Elfenbein, Perlmutt, Stahl und Silber: Pinzetten, Scheren, Badebürsten, Pinsel, Schminkläppchen und Quasten, Rückenkratzer, Schönheitspflästerchen und Feilen“ [83].

In dem legendären Roman Das Bildnis des Dorian Gray (1890) von dem englischen Schriftsteller Oscar Wilde (1854-1900) verschreibt der Protagonist für die Schönheit ewiger Jugend seine Seele:

„Als sie den Raum betraten, sahen sie an der Wand das herrliche Bildnis ihres Herrn hängen, so wie sie ihn zuletzt gesehen hatten in der ganzen Pracht und Schönheit seiner Jugend. Auf dem Boden lag ein toter Mann im Gesellschaftsanzug mit einem Messer im Herzen. Er war welk und runzlig, und sein Gesicht sah abstoßend aus. Seine Identität mit Dorian Gray konnte nur anhand der Ringe, die dieser zu tragen pflegte, festgestellt werden“ [84].

Auffälliges Schminken und aufdringliches Parfümieren sind gegen Ende des 19. Jahrhunderts verpönt und betonte Farbigkeit nur in der Demimonde üblich.

Die aufkommende Licht- und Lufttherapie für den Körper der Lebensreformbewegung stellt sich ideologisch als Gegenmodell zur viktorianischen Doppelmoral der Zeit dar.

\section{Jahrhundert}

Kosmetikimperien entstehen, Schönheit wird zunehmend machbar durch medizinisch kontrollierte Diäten und Schönheitsoperationen. Die Sportbewegung, der Körper- und Lichtkult setzen neue Akzente. Die Emanzipation der Frauen erzeugt ein neues selbstbewusstes Körperbild. Männer werden für den Kosmetikmarkt entdeckt. Die neue narzisstische Körperwahrnehmung verlangt nach ganzheitlichen Methoden, die durch die anthropologische Medizin, die Psychosomatik, die Physiotherapie und die Wellness-Konzeptionen unterstützt und verwirklicht werden.

\section{Jahrhundert}

Erst in jüngerer Zeit spielen dermatokosmetische Maßnahmen gerade in der dermatologischen Praxis wieder eine größere Rolle und es wurde vermehrt Forschungsarbeit zu dermatokosmetischen Fragestellungen geleistet, so dass im Bereich der Dermatokosmetik eine dermatologisch-medizinische Kosmetik evidenzbasiert betrieben werden kann.

\section{Ausblick}

Wie die Entwicklungsgeschichte der Kosmetik zeigte, werden die verschiedenen interdisziplinären Ansätze bezüglich der anthropologischen Körperbildästhetik auch weiterhin bestimmen, was als erstrebenswert, schön und vollkommen anzusehen sein wird.
Zur künstlichen Schönheit der Zukunft:

„Im späten 21. Jahrhundert wird es nanotechnisch möglich sein, dass Möbel, Gebäude, Kleidungsstücke, ja sogar Personen ihre äußere Erscheinung und ihre Eigenschaften in Sekundenbruchteilen ändern und sich praktisch in etwas anderes verwandeln“ [85].

Zur Körperethik der Zukunft:

„Nicht um ein Weniger oder Mehr an Körper geht es demnach in den jüngeren Veränderungen in der Geschichte des Körpers, sondern um die moralisch-ethischen, politischen, ästhetischen, medizinisch technologischen und sozialen Legitimationskontexte, die den Rahmen für die Entscheidung bilden, was ein humaner Körper ist“" [86]

\section{Literatur}

${ }^{1}$ Dülmen R v (Hrsg). Erfindung des Menschen. Schöpfungsträume und Körperbilder 1500-2000. 1. Aufl. Wien: Böhlau, 1998

2 Jockel N. Nackt. Ästhetik der Blöße. 1. Aufl. München: Prestel, 2002

3 Duerr HP. Nacktheit und Scham. Der Mythos vom Zivilisationsprozeß. 1. Aufl. Frankfurt a. M.: Suhrkamp, 1994

${ }^{4}$ Schefer Faux D. Schönheit, Beauty, Beauté. Eine Kulturgeschichte des 20. Jahrhunderts. 1. Aufl. München: Schirmer/Mosel, 2000

${ }^{5}$ Elias N. Über den Prozeß der Zivilisation, Soziogenetische und psychogenetische Untersuchungen. 19. Aufl. Frankfurt a. M: Suhrkamp, 1995

${ }^{6}$ Burgelin O (Hrsg). Vom ewigen Zwang zu gefallen, Etikette und äußere Erscheinung. 1. Aufl. Leipzig: Reclam, 1994

${ }^{7}$ Schwarzkopf H (Hrsg). Sehnsucht nach Vollkommenheit, Die Sammlung Schwarzkopf im neuen Licht im Deutschen Hygiene-Museum. 1. Aufl. Darmstadt: Die Initiative, 1995

${ }^{8}$ Jedding-Gesterling M (Hrsg). Die Frisur, Eine Kulturgeschichte der Haarmode von der Antike bis zur Gegenwart veranschaulicht an Kunstobjekten der Sammlung Schwarzkopf und internationaler $\mathrm{Mu}$ seen. 1. Aufl. Neumünster: Wachholtz, 1988

${ }^{9}$ Strate U. *apropos: Der Charme der Accessoires. Museum für Kunst und Gewerbe. 1. Aufl. Heidelberg: Umschau/Braus Verlag, 1999

${ }^{10}$ Kunstforum. Die oberflächlichen Hüllen des Selbst, Mode als ästhetisch-medialer Komplex. Kunstforum International, 1998, 141: 1-495

11 Anzieu D. Das Haut-Ich. 1. Aufl. Frankfurt a. M.: Suhrkamp, 1991

12 Benthien C. Haut. Literaturgeschichte - Körperbilder - Grenzdiskurse. 2. Aufl. Hamburg: Rowohlt, 1999

${ }^{13}$ Angeloglou M. A history of make-up. 1. Aufl. London: Studio Vista Limited, Butler \& Tanner Limited, 1970

${ }^{14}$ Lohse-Jasper R. Die Farben der Schönheit. Eine Kulturgeschichte der Schminkkunst. 1. Aufl. Hildesheim: Gerstenberg, 2000

15 Vigarello G. Wasser und Seife, Puder und Parfüm, Geschichte der Körperhygiene seit dem Mittelalter. 1. Aufl. Frankfurt a. M.: Campus, 1992

16 Stolz S. Die Handwerke des Körpers, Bader, Barbier, Perückenmacher, Friseur. Folge und Ausdruck historischen Körperverständnisses. 1. Aufl. Marburg: Jonas, 1992

17 Gosman U. Sind Sie ganz sauber? Körperkult als Seifenoper. Psychologie Heute 1996; 8: 64-67

${ }^{18}$ Labisch A. Homo Hygienicus, Gesundheit und Medizin in der Neuzeit. 1. Aufl. Frankfurt a. M.: Campus, 1992

${ }^{19}$ Schlich T. Eine kurze Geschichte der Körperverbesserung. In: Randow G v (Hrsg). Wie viel Körper braucht der Mensch. Standpunkte zur Debatte für den Deutschen Studienpreis. 1. Aufl. Hamburg: Edition Körber-Stiftung, 2001: 131 - 144

${ }^{20}$ Campsie J, Craymer C. Modern life - Strahlender Teint. 1. Aufl. Köln: Könemann, 2001

${ }^{21}$ Schoske S, Grimm A, Kreißl B. Schönheit, Abglanz der Göttlichkeit, Kosmetik im Alten Ägypten. 1. Aufl. München: Lipp, München, 1990

22 Toman R (Hrsg). Kant I. Kritik der Urtheilskraft (1790), Werke in sechs Bänden, Band 4. 1. Aufl. Köln: Könemann, 1995: 78

${ }^{23}$ Kuhn A (Hrsg). Die Chronik der Frauen. 1. Aufl. Dortmund: Chronik Verlag in der Harenberg Kommunikation Verlags- und Mediengesellschaft mbH \& Co. KG, 1992: 7 
${ }^{24}$ Helck W. Der Text des „Nilhmynus“. In: Schoske S, Grimm A, Kreißl B: Schönheit, Abglanz der Göttlichkeit, Kosmetik im Alten Ägypten. 1. Aufl. München: Lipp, 1990: 30

${ }^{25}$ Assmann I. ÄHG, 217. Nr. 92. 40 - 43. In: Schoske S, Grimm A, Kreißl B. Schönheit, Abglanz der Göttlichkeit, Kosmetik im Alten Ägypten. 1. Aufl. München: Lipp, München, 1990: 20

${ }^{26}$ Umbach W (Hrsg). Kosmetik, Entwicklung, Herstellung und Anwendung kosmetischer Mittel. 1. Aufl. Stuttgart: Thieme, 1995

${ }^{27}$ Sigismund R. Die Aromata in ihrer Bedeutung für Religion, Sitten, Gebräuche, Handel und Geographie des Alterthums bis zu den ersten Jahrhunderten unserer Zeitrechnung. 1. Aufl. Leipzig: C. F. Winter'sche Verlagshandlung, 1884

${ }^{28}$ Frazer JG. Der goldene Zweig, Das Geheimnis von Glauben und Sitten der Völker. Kulturen \& Ideen. 1. Aufl. Hamburg: Rowohlt, 1989

${ }^{29}$ Brandenburg D. Dermatologie und Kosmetik bei Herodot. Ärztliche Kosmetologie 1984; 14: 260-270

${ }^{30}$ Brandenburg D. Geschichte der Dermatologie. Mumien-Kosmetik vom Altertum bis heute. Ärztliche Kosmetologie 1985; 15: 205 - 214

${ }^{31}$ Champdor A. Das ägyptische Totenbuch in Bild und Deutung, bearbeitet von Manfred Lurker. 1. Aufl. Bindlach: Gondrom, 1992: 173

${ }^{32}$ Schott S. Altägyptische Liebeslieder. Zürich. 1950. 75. Nr. 9. In: Schoske S, Grimm A, Kreißl B. Schönheit, Abglanz der Göttlichkeit, Kosmetik im Alten Ägypten. 1. Aufl. München: Lipp, 1990: 6

${ }^{33}$ Sigismund R. Die Aromata in ihrer Bedeutung für Religion, Sitten, Gebräuche, Handel und Geographie des Alterthums bis zu den ersten Jahrhunderten unserer Zeitrechnung. 1. Aufl. Leipzig: C. F. Winter'sche Verlagshandlung, 1884

${ }^{34}$ Papyrus Boulaq. In: Roeder A. Urkunden zur Religion des alten Ägypten. 1. Aufl. Jena: Diederichs, 1915: 297

${ }^{35}$ Hölscher U. The Excavations at Medinet Habu. Bd. III. Repr. der Ausgabe 1890. Chicago: Univ. Press, 1939: 97 - 98

${ }^{36}$ Paszthory E. Salben, Schminken und Parfüme im Altertum, Herstellungsmethoden und Anwendungsbereiche im östlichen Mediterraneum. In: Antike Welt, Zeitschrift für Archäologie und Kulturgeschichte. Sondernummer 1990; 10

${ }^{37}$ Assmann J (Hrsg). Ägyptische Hymnen und Gebete. Gebet (Nr.) 118. 2. verb. u. erw. Aufl. Freiburg/Schweiz: Universitätsverlag Freiburg/ Schweiz, 1999: 267

${ }^{38}$ Glanville SRK. In: JEA 14. 1928. 297. Tf. 30 (BM 5337). In: Schoske S, Grimm A, Kreißl B. Schönheit, Abglanz der Göttlichkeit, Kosmetik im Alten Ägypten. 1. Aufl. München: Lipp, 1990: 26

39 Papyros Ebers, Das hermetische Buch über die Arzneimittel der Alten Ägypter in hieratischer Schrift Leipzig: 1875; 1. Aufl Osnabrück: Biblio, 1987

${ }^{40}$ Joachim H. Papyros Ebers. Das älteste Buch über Heilkunde. 1. Aufl. Berlin: de Gruyter, 1973: 157

${ }^{41}$ Papyrus Ebers. In: Schoske S, Grimm A, Kreißl B. Schönheit, Abglanz der Göttlichkeit, Kosmetik im Alten Ägypten. 1. Aufl. München: Lipp, 1990: 49

${ }^{42}$ Germer R. Untersuchungen über Arzneimittelpflanzen im Alten Ägypten. Diss. Hamburg: 1979

${ }^{43}$ Faure P. Magie der Düfte. Eine Kulturgeschichte der Wohlgerüche von den Pharaonen zu den Römern. 2. Aufl. München: Artemis \& Winkler 1991

${ }^{44}$ Rimmel E. Das Buch des Parfums, Die Klassische Geschichte des Parfums und der Toilette. 1. Aufl. Dreieich: Weiss, 1985: 93

${ }^{45}$ Rimmel E. Das Buch des Parfums, Die Klassische Geschichte des Parfums und der Toilette. 1. Aufl. Dreieich: Weiss, 1985: 164

${ }^{46}$ Hesiod. Theogonie. V. 187-200. In: Ströter-Bender J. Liebesgöttinnen. Von der Großen Mutter zum Hollywoodstar. 1. Aufl. Köln: Dumont, 1994: 24

${ }^{47}$ Homer. Hymnen. 6. Auf Aphrodite. 5 - 13. In: Ströter-Bender J. Liebesgöttinnen. Von der Großen Mutter zum Hollywoodstar. 1. Aufl. Köln: Dumont, 1994: 173

48 Platon. Sämtliche Werke, Band V, Politikos, Philebos, Timaios, Kritias. Ernesto Grassi (Hrsg). Rowohlts Klassiker der Literatur und Wissenschaft, Griechische Philosophie Band 6. 12. Aufl. Hamburg: Rowohlt, 1980: 197, Abschnitt 76a-e

${ }^{49}$ Antiphanes A. Antea. In: Rimmel E. Das Buch des Parfums. Die klassische Geschichte des Parfums und der Toilette. 1. Aufl. Dreieich: Hesse \& Becker, 1985: 111

${ }^{50}$ Kenney EJ (Hrsg). Ovidi Nasonis P. Amores, Medicamina faciei femineae, Ars amatoria, Remedia Amoris. Editit, Brevique Adnotatione Critica. 9. Aufl. Oxford: Oxford University Press, 1989: 105
${ }^{51}$ Schmolke-Hasselmann B. Camuse Chose. Das Häßliche als ästhetisches und menschliches Problem in der altfranzösischen Literatur. In: Zimmermann A (Hrsg). Die Mächte des Guten und des Bösen, Bd. 11. 1. Aufl. Berlin: de Gruyter, 1977: 442 - 452

52 Clairvaux Bernhard v. Sermones super Cantica Canticorum. In: Eco U. Kunst und Schönheit im Mittelalter. 3. Aufl. München: DTV Wissenschaft, 1995: 23

${ }^{53}$ Mohrungen H v. Lyrik. In: Foerster RH. Das Leben in der Gotik. 1. Aufl. München: Hueber, 1977: 122

54 Toellner R. Illustrierte Geschichte der Medizin. Genehmigte Sonderauflage. Salzburg: Andreas \& Andreas, 1986

${ }^{55}$ Burckhardt J. Die Kultur der Renaissance in Italien. 1. Aufl. Herrsching: Pawlak, 1981

${ }^{56}$ Dülmen R v. Die Entdeckung des Individuums, 1500-1800. 2. Aufl. Frankfurt a. M: Fischer, 2002

${ }^{57}$ Belting H. Bild-Anthropologie, Entwürfe für eine Bildwissenschaft. 2. Aufl. München: Fink, 2002

58 Castiglione B. Der Hofmann, Lebensart in der Renaissance. 1. Aufl. Berlin: Wagenbach, 1996: 69-70

${ }^{59}$ Castiglione B. Der Hofmann, Lebensart in der Renaissance. 1. Aufl. Berlin: Wagenbach, 1996: 43

${ }^{60}$ Jeggle U. Alltag. In: Stolz S. Die Handwerke des Körpers, Bader, Barbier, Perückenmacher, Friseur. Folge und Ausdruck historischen Körperverständnisses. 1. Aufl. Marburg: Jonas, 1992: 146

61 Vigarello G. Wasser und Seife, Puder und Parfüm, Geschichte der Körperhygiene seit dem Mittelalter. 1. Aufl. Frankfurt a. M.: Campus, 1992

62 Corbin A. Pesthauch und Blütenduft, Eine Geschichte des Geruchs. 1. Aufl. Berlin: Wagenbach, 1984

${ }^{63}$ Le Long M. Le Régime de santé de l'école de Salerne. 1. Aufl. Paris: 1633: 19

${ }^{64}$ Foerster RH. Die Welt des Barock, Hueber, 1. Aufl. München: 1977: 161

${ }^{65}$ Le Mercure galant. Paris: 1677 Juillet, 274

${ }^{66}$ Réglements des réligieuses ursulines. In: Vigarello G. Wasser und Seife, Puder und Parfüm, Geschichte der Körperhygiene seit dem Mittelalter. 1. Aufl. Frankfurt a. M., New York: Campus, 1992: 95

${ }^{67}$ Foerster RH. Die Welt des Barock, Hueber, 1. Aufl. München: 1977: $313-314$

68 Goncourt E, Goncourt J. Die Frau im 18. Jahrhundert. In: Corbin A. Pesthauch und Blütenduft, Eine Geschichte des Geruchs. 1. Aufl. Berlin: Wagenbach, 1984: 90

${ }^{69}$ Schultz A. Alltagsleben einer deutschen Frau zu Anfang des 18. Jahrhunderts. 1. Aufl. Leipzig: Hirzel, 1890

${ }^{70}$ Liggett A, Liggett J. Die Tyrannei der Schönheit. 1. Aufl. München: Heyne, 1990

${ }^{71}$ Schultz A. Alltagsleben einer deutschen Frau zu Anfang des 18. Jahrhunderts. 1. Aufl. Leipzig: Hirzel, 1890: 62

72 Goncourt E, Goncourt J. Die Frau im 18. Jahrhundert. In: Stolz S. Die Handwerke des Körpers, Bader, Barbier, Perückenmacher, Friseur. Folge und Ausdruck historischen Körperverständnisses. 1. Aufl. Marburg: Jonas, 1992: 156

${ }^{73}$ Anmuth und Schönheit aus den Misterien der Natur und Kunst für ledige und verheirathete Frauenzimmer mit Kupfern. Berlin 1797. Reprint der bibliophilen Taschenbücher. 1. Aufl. Dortmund: Harenberg Kommunikation, 1978: $171-178$

74 Anmuth und Schönheit aus den Misterien der Natur und Kunst für ledige und verheirathete Frauenzimmer mit Kupfern. Berlin 1797. Reprint der bibliophilen Taschenbücher. 1. Aufl. Dortmund: Harenberg Kommunikation, 1978: 182

${ }^{75}$ Anmuth und Schönheit aus den Misterien der Natur und Kunst für ledige und verheirathete Frauenzimmer mit Kupfern. Berlin 1797. Reprint der bibliophilen Taschenbücher. 1. Aufl. Dortmund: Harenberg Kommunikation, 1978: 207

${ }^{76}$ Garve C. Über die Moden (1792). 1. Aufl. Frankfurt a. M.: Insel, 1987: 51

77 Böhmer G. Die Welt des Biedermeier. 1. Aufl. München: Hueber, 1977

${ }^{78}$ Lütkehaus L (Hrsg). Arthur Schopenhauers Werke in fünf Bänden. Parerga und Paralipomena II. Band 5. 1. Aufl. Zürich: Haffmans, 1988: 546

${ }^{79}$ Gollmann W. Toilette-Lexikon für die elegante Welt. Kosmetisches Nachschlagebuch für Damen und Herren zur Erhaltung und Erhöhung ihrer Schönheit, Anmuth und Gesundheit. 1. Aufl. Leipzig: Dr. Wilhelm Gollmann, Verlag von Franz Wagner, 1860: 86

${ }^{80}$ Gollmann W. Toilette-Lexikon für die elegante Welt. Kosmetisches Nachschlagebuch für Damen und Herren zur Erhaltung und Erhöhung ihrer Schönheit, Anmuth und Gesundheit. 1. Aufl. Leipzig: Dr. Wilhelm Gollmann, Verlag von Franz Wagner, 1860: 111 
81 Baudelaire C. Les Fleurs du Mal (Die Blumen des Bösen). 1. Aufl. Stuttgart: Reclam, 1980: 78

82 Haubl R. „Unter lauter Spiegelbildern...“, Zur Kulturgeschichte des Spiegels. 1. Aufl. Frankfurt a. M.: Nexus, 1991

${ }^{83}$ Huysmans JK. Gegen den Strich. 1. Aufl. München: DTV, 1995: 145

${ }^{84}$ Wilde O. Das Bildnis des Dorian Gray. 1. Aufl. Frankfurt a. M., Berlin, Wien: Ullstein, 1980: 200
85 Kurzweil R. Homo s@piens. Leben im 21. Jahrhundert - Was bleibt vom Menschen? 2. Aufl. Köln: Kiepenheuer \& Witsch, 1999: 223

${ }^{86}$ Klein G. Der Körper als Erfindung. In: Randow, Gero v (Hrsg). Wie viel Körper braucht der Mensch. Standpunkte zur Debatte für den Deutschen Studienpreis. 1. Aufl. Hamburg: Edition Körber-Stiftung, 2001: 62

\section{Aktuelles Interview}

\section{Eine neue Therapieoption für den „Damenbart“?}

\section{Prof. Dr. E. G. Jung, Heidelberg:}

Für den idiopathischen Hirsutismus kennen wir bereits einige nicht ganz angenehme Therapiemethoden, z.B. das Auszupfen, das Bleichen, die Wachs-Epilation, die Nadelepilation und Laserepilationsmethoden. Seit Herbst 2004 ist eine Creme in Deutschland zugelassen, die Eflornithin enthält. Wie ist diese Therapieoption einzuordnen?

\section{Prof. Dr. C. Bayerl, Mannheim:}

Die Creme enthält Eflornithin (Difluoromethylornithin) 11,5\% als Hydrochlorid (Vaniqa ${ }^{\circledR}, 15 \mathrm{~g}, 30 \mathrm{~g}, 60 \mathrm{~g}$, Gillette/Bristol-MyersSquibb, über Shire Deutschland GmbH, Köln) und ist in den USA schon seit Jahren FDA-, in Europa EMEA- zugelassen und jetzt auch bei uns erhältlich für Frauen, „um übermäßigen Haarwuchs im Gesicht zu verringern". Eflornithin hemmt irreversibel die Ornithin-Decarboxylase (ODC), ein Enzym, das an der Bildung des Haarschaftes beteiligt ist und verlangsamt dadurch das Haarwachstum. Die Creme wird zweimal täglich aufgetragen und soll einmassiert werden. Eine Enthaarung im eigentlichen Sinne findet nicht statt. Der klinische Effekt ist ab der 8. Behandlungswoche zu erwarten und zeigt sich als Reduktion des Gesichtshaarwachstums um $60 \%$, wie in mehreren klinischen Studien gezeigt wurde. Eine Studie über 24 Wochen $(n=594)$ zeigte eine signifikante Besserung gegenüber der Cremegrundlage (Kategorien rein/fast rein, deutliche Besserung, Besserung). Besonders deutlich war der Effekt bei Frauen nach den Wechseljahren an den typischen Problemlokalisationen Oberlippe und Kinn. Warum die Substanz bei manchen Frauen gar nicht wirkt, ist bisher nicht bekannt. 8 Wochen nach Therapieabbruch, war der Ausgangszustand wieder erreicht. Die Substanz hat eine Halbwertszeit von 8 Stunden und wird über die Niere ausgeschieden [1]. Vaniqa ist rezeptpflichtig, ab dem 12. Lebensjahr zugelassen, wurde bei Patienten mit schweren Nierenfunktionsstörungen nicht untersucht, hat keine Wechselwirkungen mit anderen Arzneimitteln, soll jedoch in Schwangerschaft und Stillzeit nicht angewandt werden. Es kommt selten zu einem leichten Kribbeln, Brennen oder Rötung an der Haut $(>1 \%$ bis $<10 \%)$, mitunter zu einer leichten Akne (> 10\%) [2].

Ursprünglich wurde und wird das Präparat zur Behandlung der Trypanosoma brucei gambiense-Infektion (afrikanische Schlafkrankheit) eingesetzt. Orale Aufnahme bei Schlafkrankheit hat zu Haarausfall geführt [3]. Da die kutane Penetration gering ist, sind die dort beschriebenen Nebenwirkungen wie Hörschäden, Krampfanfälle und gastrointestinale Störungen, Thromozytope- nie und Leukopenie bei der topischen Anwendung nicht aufgetreten.

Die Produktion dieser sehr effektiven Substanz gegen Schlafkrankheit war 1995 durch Aventis/Hoechst Marion Roussel gestoppt worden, da die Produktion keinen Profit erbrachte. Zusammen mit der Einführung von Eflornithin gegen vermehrte Gesichtbehaarung bei Frauen wurde der öffentliche Druck so groß, dass die lebensrettende Substanz bereit gestellt wurde. Im Rahmen eines WHO-Projektes zur medikamentösen Versorgung, Erfassung, Behandlung und Forschung unterstützen Aventis, Bayer und Bristol-Myers-Squibb mit \$25 Millionen ein Programm (2001-2006), die Schlafkrankheit auszurotten, einschließlich der Bereitstellung von Eflornithin (International Federation of Pharamaceutical Manufactureres \& Associations, www.ifpma.org/Helath/other_infect/health_sleep.aspx; Medicins Sans Frontieres, www.msf.org/content/ ...)

Interessanterweise hat Eflornithinhydrochlorid ebenfalls eine Antitumorwirkung in Zellkultur und Tumormodellen in vivo [4]. Die Substanz ist ein spezifischer Inhibitor der ODC, einem essentiellen Enzym in der Polyaminbiosynthese. ODC und Polyamine werden in epithelialen Tumoren der Haut, Tumoren des Kolons und Pankreas in erhöhten Konzentrationen gefunden [5]. In klinischen Studien konnte die Substanz dahingehend bisher nicht überzeugen.

Nach eigenen klinischen Erfahrungen ist der für die Gesichtshaut beschriebene Effekt auch an den Unterschenkeln zu erzielen, ersetzt aber auch hier nicht die Epilation. Ein sinnvolle Anwendung könnte auch die Pseudofollikulitis barbae darstellen, jedoch liegen bisher keine Daten zur Wirkung bei Männern vor

\section{Literatur}

${ }^{1}$ Malhotra B, Noveck R, Behr D, Palmisano M. Percutaneous absorption and pharmacokinetics of eflornithine $\mathrm{HCl} 13,9 \%$ cream in women with unwanted facial hair. J Clin Pharmacol 2001; 41: 972 - 978

${ }^{2}$ Hickman JG, Huber F, Palmisano M. Human dermal safety studies with eflornithine HCL 13.9\% cream (Vaniqa), a novel treatment for excessive facial hair. Curr Med Res Opin 2001; 16: 235-244

${ }^{3}$ Pepin J, Milford F, Guern C, Schechter PJ. Difluoromethylornithine for arseno-resistant Trypanosoma brucei gambiense sleeping sickness. Lancet $1987 \cdot 2 \cdot 1431-1433$

${ }^{4}$ Griffin CA, Slavik M, Chien SC, et al. Phase I trial and pharmacokinetic study of intravenous and oral alpha-difluoromethylornithine. Invest New Drugs 1987, 5: 177-186

${ }^{5}$ Wheeler DL, Ness KJ, Oberley TD, Verma AK. Inhibition of the development of metastatic squamous cell carcinoma in protein kinase $C \varepsilon$ transgenic mice by $\alpha$-difluoroethylornithine accompanied by marked hair follicle degeneration and hair loss. Cancer Research 2003; 63: $3037-3042$ 